\title{
Complete Dorsal Wall Agenesis of Sacrum: A Case Report
}

\author{
Vanitha $^{1}$, Taqdees Fatima ${ }^{2}$, H. S. Kadlimatti ${ }^{3}$ \\ ${ }^{1,2,3}$ (Department of Anatomy, ESIC Medical College Gulbarga/ Rajiv Gandhi university of health \\ Sciences, Karnataka, India)
}

\begin{abstract}
Sacrum is a triangular bone wedged between two innominate bones. It is formed by fusion of five sacral vertebrae. Forms the caudal region of the vertebral column. Base articulates with lumbar vertebra and apex with coccyx. Pelvic surface is concave and dorsal is convex encloses a triangular sacral canal .During demonstration classes for undergraduate medical students we observed that sacrum with agenesis of dorsal wall and first sacral lamina showing incomplete fusion thus forming open sacral canal posteriorly.The knowledge of this variation may be of importance to orthopaedic surgeons, neurosurgeons, radiologists and anthropologists.
\end{abstract}

Keywords: Agenesis, hiatus, ossification, sacrum, vertebrae.

\section{Introduction}

Sacrum is triangular bone formed by fusion of five sacral vertebrae and forms posterosuperior wall of the pelvic cavity, wedged between two innominate bones. Its base projects upwards and forwards and articulates with the last lumbar vertebra to form a prominent sacrovertebral angle, while truncated apex points downwards and articulates with the coccyx.Sacrum ossified by appearing of primary centres for centrum and each half of vertebral arch between tenth and twentieth week. For costal element primary centres appear at the time of sixth and eighth month of prenatal month [1]. It usually consists of five unfused vertebrae which begin to fuse between 16-18 years of age and are usually completely fused to form a single piece of bone by 34 years of age. Its dorsal surface is convex and narrower than the pelvic surface. In the midline is the middle sacral crest, surmounted by three or four tubercles representing the spinous processes of the upper three or four sacral vertebrae.On the sides of middle sacral crest is a shallow groove which gives origin to the Multifidus. The floor of the groove is formed by the united laminae of the corresponding sacral vertebræ. The laminae and spinous process of the fifth and /or fourth sacral vertebrae fail to meet in the mid line creating a deficiency known as the hiatus in the posterior wall of the sacral canal. The hiatus is covered by skin, a subcutaneous fatty layer and the sacrococcygeal membrane [2]. Sacral hiatus has been utilized for administration of epidural anaesthesia in obstetrics [3] as well as in orthopaedic practice for treatment and diagnosis [2].

\section{Case report}

During osteology demonstration classes for undergraduate students we observed a dry human sacrum with dorsal wall agenesis and the lamina of first sacral vertebra was present but showing incomplete fusion. Remaining features of the sacrum were normal [figure 1].

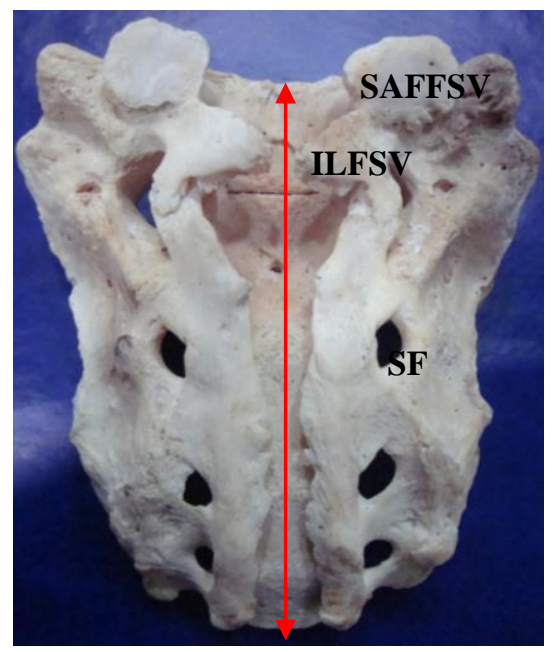

Figure 1: showing complete dorsal wall agenesis [arrow mark], ILFSV: Incomplete Lamina of First Sacral Vertebra, SF: Sacral Foramina ,SAFFSV: Superior Articular Facet of First Sacral Vertebra. 


\section{Discussion}

In this case study sacrum shows agenesis of dorsal wall because of failure of fusion of sacral laminae. Seema et al.,studied 159 sacra for the variations of sacral hiatus, found various shapes of sacral hiatus which included inverted U(42.95\%), inverted V (27.51\%), irregular (16.10\%), dumbbell (11.40\%) and bifid (2.01\%). The apex of sacral hiatus was commonly found at the level of 4th sacral vertebra in $56.36 \%$. And also they found that complete agenesis of dorsal bony wall of sacral canal in 3.14\% sacra [4]. 1.5\% sacra show dorsal wall agenesis in 270 dry sacra [5]. Jhenneberg et al., observed $3 \%$ of sacra with complete dorsal wall agenesis out of 124 adult sacra [6]. Trotter et al.,have observed 1.8\% [7] and Kumar et al., have observed 1.49\% of sacra with complete absence of dorsal wall [8].Senogluet al., have observed $2.08 \%$ of sacra having total posterior closure defect [9]. Sound knowledge of position, shape and the morphology of sacral canal are important for caudal epidural anaesthesia. Surgical treatment of sacral lesions requires understanding of the underlying anatomy and various morphometric parameters of sacrum. Significant leaps have been made towards the understanding of the sacral region by both anatomists and surgeons,there is still much to be learned with advances in surgical methods and instrumentation in the field of spinal surgery driving a continued need to better understand the anatomy of the region [10].

\section{Conclusion}

It's a rare variation having knowledge about this may be useful for orthopaedic surgeons, neurosurgeons, radiologists and anthropologists and during caudal epidural anaesthesia. Understanding of these variations may improve the reliability of caudal epidural block.

\section{References}

[1]. Harold Ellis, Patricia Collins, David Johnson, skeletal system,Gray's Anatomy; The anatomical basis of clinical practice $38^{\text {th }}$ edn.; pp.533,Churchill Livingstone,London.

[2]. SekiguchiM,Yabuki S, Satoh K. And KikuchiS.;an anatomical study of the sacral hiatus: a basis for successful caudal epidural block.clin.J.pain, 20(1):1-4, 2004.

[3]. Edward W.B., Hingson R.A.; continuous caudalanesthesia in obstetrics. Am.J.Surg. 7; 459-64, 1942.

[4]. Seema, Singh M \& Mahajan A; An anatomical study of variations of Sacral hiatus in sacra of north Indian origin and its clinical significance:Int.J.Morphol.31(1):110-114,2013.

[5]. Nagar SK. A study of Sacral Hiatus in dryhuman sacra.Journal of Anatomical Society of India; 53(2):18-21:2004

[6]. Renata Jhenneberg and Macie Jhenneberg; variation in the closure of sacral canal skeletal sampl from the Pompeii, Italy 79 ad: perspectives in human biology vol 4(1):177-188: 1999.

[7]. Trotter M. Variations of the sacral canal.Their significance in administration of caudal analgesia. Anaesthesia and analgesia. 1947; 26(5):192-202.

[8]. Vinod Kumar, Pandey SN,Bajpai RN et al. Morphometrical study of sacral hiatus. Anat.Soc of India1992; 41(1):7-13

[9]. Senoglu N, Senoglu M, Oksuz H, Landmarks of the sacral hiatus for caudal epidural block: an anatomical study. BritishJournal of Anaesthesia.95(5):692-5, 2005

[10]. Swathi PoornimaC; complete dorsal wall defect in dry human sacrum: a case report; IJMRHS; 2013:2(2); $290-292$. 